\title{
Re-examining the influence of the inclusion characteristics on the drying shrinkage of cementitious composites
}

\author{
Galen Egan ( $\left(^{*}\right)$, Aditya Kumar $\left({ }^{+}\right)$, Narayanan Neithalath $\left({ }^{\ddagger}\right), \operatorname{Gaurav} \operatorname{Sant}\left(\left(^{\S},{ }^{* *}, 1\right)\right.$
}

\begin{abstract}
The addition of aggregates to cement paste is known to alter its shrinkage, in relation to the aggregate stiffness and volume fraction. This study reexamines the effects of aggregate volume, and stiffness on shrinkage experienced upon $1^{\text {st }}$ and $2^{\text {nd }}$ drying, by cement pastes across a range of $\mathrm{w} / \mathrm{c}$ (water-to-cement ratio, mass basis). Special focus is paid to understand the influence of the volume and properties of inclusions on the shrinkage response. By unifying shrinkage and mass loss relations with sorption isotherms, the moisture transport properties are extracted as a function of drying time and external relative humidity $(\mathrm{RH})$.
\end{abstract}

Keywords: drying, shrinkage, moisture diffusion, inclusions, transport, elastic modulus

\footnotetext{
* Laboratory for the Chemistry of Construction Materials $\left(\mathrm{LC}^{2}\right)$, Department of Civil and Environmental Engineering, University of California, Los Angeles, CA 90095

${ }^{+}$Department of Materials Science and Engineering, Missouri University of Science and Technology, Rolla, MO 65409

${ }^{\ddagger}$ School of Sustainable Engineering and the Built Environment, Arizona State University, Tempe, AZ 85287

${ }^{\S}$ Laboratory for the Chemistry of Construction Materials $\left(\mathrm{LC}^{2}\right)$, Department of Civil and Environmental Engineering, University of California, Los Angeles, CA 90095

${ }^{* *}$ California Nanosystems Institute, University of California, Los Angeles, CA 90095

${ }^{1}$ Corresponding Author: Email: gsant@ucla.edu, Phone: (310) 206-3084, Fax: (310) 206-2222
}

(C) 2017. This manuscript version is made available under the Elsevier user license 


\subsection{Introduction and Background}

From an economic and environmental standpoint, it is important that concrete structures achieve the longest service-life possible. However, a major drawback of this ubiquitous material is its tendency to shrink upon drying, which results in cracking, thereby accelerating the ingress of deleterious agents (water, $\mathrm{Cl}^{-}$ions) which causes the premature degradation of structures $\left[{ }^{1}, 2\right]$. Over several decades, extensive efforts have been devoted to better understand the shrinkage of cement pastes, mortars and concretes, and novel methods

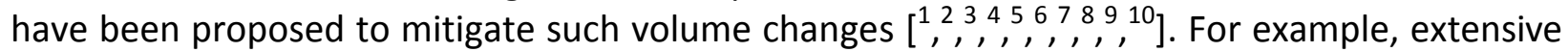
efforts have been made to assess the effects of the paste's $w / c$ on shrinkage $\left[{ }^{1,4}\right]$. In general, higher $\mathrm{w} / \mathrm{c}$ pastes have been noted to shrink more than their lower w/c counterparts. This has been widely attributed to the higher evaporable water content and the reduced stiffness of the matrix in cement pastes prepared at higher $\mathrm{w} / \mathrm{c}\left[{ }^{1},{ }^{2}\right]$. Other studies have attempted to describe moisture loss and shrinkage behavior of mortar and concrete as a function of the aggregate dosage and properties using "composite models", e.g., see $\left[\begin{array}{c}2, \\ ,\end{array}\right]$.

While substantial insights regarding the drying and shrinkage of cementitious materials has been gained, several questions regarding aggregate permeability and its role on drying and on shrinkage remain unclear. For example, while several studies have shown a linear relationship between mass (water) loss during drying, and shrinkage developed $\left[{ }^{1},,^{4}, 11\right]$ these relationships have not been carefully analyzed to draw inferences of inclusion permeability (and

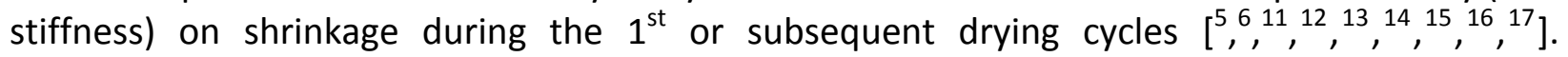
Therefore, this paper seeks to evaluate the following aspects:

- Re-examine the effects of stiffness, size, and volume dosage (\%) of aggregates (subsequently referred to as inclusions) on shrinkage, and to assess the predictive capability of Pickett's and Hobbs models in shrinkage estimation $\left[\begin{array}{l}2,5 \\ ,\end{array}\right]$,

- Critically assess shrinkage trends up on $1^{\text {st }}$ drying, and following rewetting, up on $2^{\text {nd }}$ drying, to assess the extent of shrinkage irreversibility, and its relation to inclusion properties, and,

- Assess the transport properties (e.g., diffusion coefficients, intrinsic permeability) of cement-based mixtures across drying cycles, and relate these to changes to microstructural changes.

The outcomes improve our understanding of the shrinkage behavior of cementitious materials, and thereby improve our ability for shrinkage prediction.

\subsection{Methods and Materials}

An ASTM C150 compliant Type I/II ordinary portland cement (OPC) with an estimated phase composition (on mass basis) of: $56.5 \% \mathrm{C}_{3} \mathrm{~S}, 18 \% \mathrm{C}_{2} \mathrm{~S}, 6.3 \mathrm{C}_{3} \mathrm{~A}, 11.4 \% \mathrm{C}_{4} \mathrm{AF}$ and $0.5 \% \mathrm{Na}_{2} \mathrm{O}$ equivalent was used $\left[{ }^{18}\right]$. The inclusions used were "stiff" and "soft" inclusions. The stiff inclusions comprised: (a) an ASTM C778 compliant graded quartz sand, and, (b) nominally pure, limestone powder with median particle sizes of $\left(d_{50}, \mu \mathrm{m}\right): 3 \mu \mathrm{m}, 15 \mu \mathrm{m}$, and $40 \mu \mathrm{m}$. The soft inclusions comprised a paraffin based microencapsulated phase change material (PCM), Micronal ${ }^{\circledR}$ DS $5008 X$ supplied by BASF Corporation. The PCM is supplied as a powder and has a phase change temperature around $23^{\circ} \mathrm{C}$, and a latent heat $\left(\Delta \mathrm{H}_{\mathrm{PCM}}\right)$ capacity of $\approx 110 \mathrm{~kJ} / \mathrm{kg}$ respectively $\left[{ }^{19}\right]$. The density of the $\mathrm{OPC}, \mathrm{PCM}$, limestone and quartz inclusions were estimated as $3150 \mathrm{~kg} / \mathrm{m}^{3}, 300 \mathrm{~kg} / \mathrm{m}^{3}, 2700 \mathrm{~kg} / \mathrm{m}^{3}$ and $2650 \mathrm{~kg} / \mathrm{m}^{3}$ respectively. The particle size 
distributions (PSDs; Figure 1) of the solids were measured using static light scattering (SLS) using a Beckman-Coulter analyzer. Isopropanol and ultra-sonication were used to disperse the powders to primary particles. The uncertainty in the SLS data was determined to be on the order of $6 \%$ based on measurements of six replicate samples.

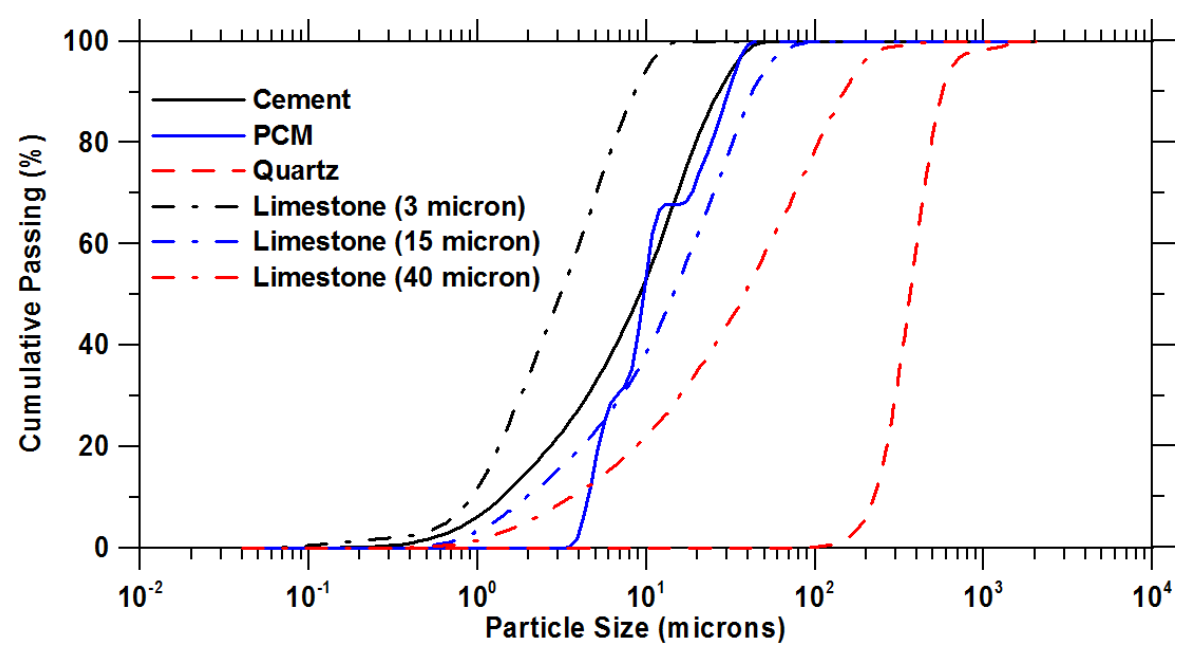

Figure 1: The particle size distributions (PSDs) of the OPC, PCM, limestone and quartz used in this study as measured using static light scattering (SLS).

Cement paste mixtures were prepared using de-ionized water at fixed $w / c(w / c=0.45$, $\mathrm{w} / \mathrm{c}=0.55$, and $\mathrm{w} / \mathrm{c}=0.65$, mass basis) as per ASTM C305 $\left[{ }^{20}\right]$. Mixtures containing inclusions were prepared in the form of mortars, using the PCM, limestone or quartz sand as inclusions, while keeping the $\mathrm{w} / \mathrm{c}$ constant. The volume $\%$ of inclusions in the mixtures ranged between 0 to-50\%. After mixing, the pastes were cast into prismatic molds maintained over deionized water for 24 hours after which they were de-molded, and placed in limewater (i.e., under immersion) until 56 days, after which further evaluations were carried out.

Unrestrained drying deformations were measured on prismatic cement paste and mortar samples per ASTM C157. The samples were maintained at $25 \pm 0.2^{\circ} \mathrm{C}$ and $50 \pm 0.2 \% \mathrm{RH}$ $\left[{ }^{20}\right]$. Both length change and mass loss were recorded at drying times of: $1,3,7,28,56,90,135$, 180, 225 and 270 days; after drying was initiated at an age of 56 days. The length change reported is the average of four specimens with a measuring accuracy of $\pm 10 \mu \varepsilon$. Before drying was initiated, the prismatic samples were sealed on four sides (i.e., so that only two parallel, long sides remained open) with two layers of aluminum tape to ensure 1-D drying. Over the drying period between 1 and 270 days, the internal $\mathrm{RH}$ of the samples is expected to decrease progressively from $\approx 100 \%$ (i.e., saturation) to $\approx 50 \%$ with increasing drying time as equilibrium is attained.

Due to large differences between the ambient $\mathrm{RH}(50 \%)$ and the initial internal $\mathrm{RH}$, the egress of moisture from the sample and the resulting shrinkage, particularly at short drying times is expected to occur at higher rates as compared to that occurring after longer drying times. This implies that the measurements of mass loss and shrinkage pertain to a mixture of 
highly non-equilibrium (i.e., shorter drying times) and near-equilibrium (i.e., longer drying times) conditions. While it may be argued that the large dimensions (i.e., 1-inch thickness) of the samples would induce the development of moisture-/shrinkage-gradients, and potentially produce microcracks in the surface region; the " 1 inch" geometry and the single-RH (50\%) drying regime was adopted to acquire data using a standardized procedure (ASTM C157). Of course, ideally, while it would be desirable to dry thin samples (a few "mm" in thickness, e.g.,

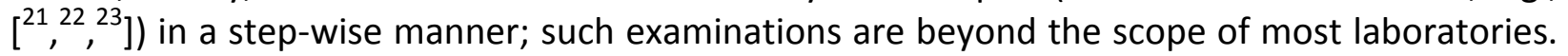
As such, this study places focus on describing overall trends in mass loss and shrinkage while acknowledging the potential existence of moisture and shrinkage gradients in the samples, especially at early-drying times.

After 270 days of drying, when shrinkage is near-equilibrium (see Figure 3 for the criteria by which mass and deformation "equilibrium" was established), the samples were unsealed and rehydrated in limewater for 28 days. After such resaturation, the samples were resealed and their mass loss and length change were recorded over the $2^{\text {nd }}$ drying cycle, at the same time intervals as considered during the $1^{\text {st }}$ drying cycle.

\subsection{An Overview of Moisture Loss Driven Shrinkage and its Influencing Parameters}

For drying at $\mathrm{RH}=50 \%$, capillary stresses are the primary driving force for shrinkage $\left[{ }^{24}\right]$. The capillary stress developed is described by the Kelvin-Laplace relation which is written as:

$$
P_{C}=\frac{2 \gamma_{L V} \cos \theta}{r_{M}}=\frac{\ln (R H / 100) R T}{V_{M}}
$$

qhere, $P_{C}$ is the capillary pressure $(\mathrm{GPa}) \gamma_{\mathrm{LV}}$ is the surface tension of the pore-fluid at the liquidvapor interface $(72.8 \mathrm{mN} / \mathrm{m}$ for pure water), $\theta$ (degrees) is the contact angle between the solidliquid interface at the pore meniscus (assumed to be $0^{\circ}$ ), $\mathrm{r}_{\mathrm{M}}$ is the Kelvin radius (negative in the case of drying, $\mathrm{m}), \mathrm{RH}$ is the relative humidity $(50 \% \mathrm{RH}), \mathrm{R}$ is the gas constant ( $8.314 \mathrm{~J} / \mathrm{K} . \mathrm{mole}), \mathrm{T}$ is the thermodynamic temperature $(\mathrm{K})$ and $\mathrm{V}_{\mathrm{M}}\left(\mathrm{m}^{3} / \mathrm{mole}\right)$ is the molar volume of water. The linear shrinkage that develops due to the imposition of drying stresses can be described by Mackenzie's formulation, as amended by Bentz et al., to consider the effects of partial liquid saturation of the pores, for a linear-elastic body as shown in Equation (2) $\left[{ }^{25},{ }^{26}\right]$ :

$$
{ }_{L}=\frac{S P_{C}}{3}\left(\frac{1}{K_{B}} \frac{1}{K_{S}}\right)
$$

where, $\varepsilon_{L}$ is linear deformation $(\mu \mathrm{m} / \mathrm{m}), S$ is degree of liquid saturation $(0 \leq S \leq 1), K_{B}$ is the bulk modulus of the composite (GPa), and $\mathrm{K}_{\mathrm{S}}$ is the bulk modulus of its solid-skeleton (GPa), i.e., not considering the porosity. It should be noted that during drying, the capillary pressure developed is tensile and thereby exerts a compressive (i.e., shrinkage inducing) stress on the pore walls. The relation between the bulk and skeletal modulus can be described by Equation (3) $\left[{ }^{27}\right]$, where $\phi$ is the volumetric porosity (unitless, ratio of the volume of pores to the bulk volume). 


$$
K_{B}=K_{S}(1 \quad)^{2}
$$

Expectedly, Equations (2-3) can be combined to estimate the linear shrinkage $\left(\varepsilon_{\mathrm{L}}\right)$ of a cement paste, mortar or concrete as shown in Equation (4).

$$
=\frac{S P_{C}}{3 K_{S}}\left(\frac{1}{(1 \quad)^{2}} \quad 1\right)
$$

Equation (4) can be analyzed to assess the influence of each variable on the shrinkage strain experienced by a body. While the interrelations are complex (e.g., see Sant et al. $\left[^{8}\right]$ ), some cases can be discussed wherein the exposure $\mathrm{RH}$ is fixed (e.g., $\mathrm{RH}=50 \%$ ), thus resulting in fixed impositions of capillary pressure (and shrinkage stresses):

- A material with higher porosity will shrink more than a material having a lower porosity, in spite of having the same skeletal modulus and similar pore size distributions. This is because $\mathrm{K}_{\mathrm{B}}$ degrades substantially with increasing porosity ( $1^{\text {st }}$ order effect). Even if it is argued that at a given $\mathrm{RH}$ (e.g., between $10 \%$ and $90 \%$ ), a more porous material would show a lower liquid saturation level (i.e., due to enhanced water removal per unit volume of solid), this $2^{\text {nd }}$ order effect is more than compensated by the reduction in $\mathrm{K}_{\mathrm{B}}$. If differences in porosity between the two materials are negligible, it is possible that the effects of a slightly higher $\mathrm{K}_{B}$ and slightly higher liquid saturation for the less porous solid, and slightly lower $\mathrm{K}_{\mathrm{B}}$ and lower saturation for the more porous solid may counterbalance each other. Herein, the shrinkage developed would be similar, due to compensation effects rather than the (dis)similarity in properties.

- The discussion above becomes more complex if of the two parameters, i.e., porosity $(\phi)$ and pore size distribution, one is similar while the other differs between two solids with similar skeletal moduli. For example: due to the impacts of the pore size distribution on both $\mathrm{K}_{\mathrm{B}}$ and $\mathrm{S}$, a material with (a higher volume fraction, but not exceedingly so of) larger pores would shrink less than a material with finer pores, despite both materials having similar $\mathrm{K}_{\mathrm{S}}$ and $\phi$; due to the lower liquid saturation level in the former material.

As such, for high and low w/c cement pastes, under conditions of external drying, high $\mathrm{w} / \mathrm{c}$ pastes will shrink more than lower $\mathrm{w} / \mathrm{c}$ pastes, due to the larger porosity (i.e., lower $\mathrm{K}_{\mathrm{B}}$ ) of the former - which is far is more influential in dictating shrinkage than the liquid saturation level. This assumes: (a) similar pore-size distribution but not total pore volumes for the high and low w/c pastes, (b) that $K_{s}$ is insensitive to w/c; as noted by Grasley et al. $\left[{ }^{28}\right]$, and, (c) early age self-desiccation effects are absent, a valid assumption herein since all pastes feature $\mathrm{w} / \mathrm{c}>0.42$ $\left[{ }^{29}\right]$.

\subsection{Experimental Results and Discussion: Mass Loss and Drying Shrinkage}




\subsection{The Influence of $w / c$, Inclusion Properties and Model Predictions}

Figures 2-3 show the evolutions of shrinkage as a function of the drying time for mixtures containing different volume fractions of limestone, quartz, and PCM inclusions for two different $\mathrm{w} / \mathrm{c}$. At a given age, pastes with a higher $\mathrm{w} / \mathrm{c}$ shrink more than their lower $\mathrm{w} / \mathrm{c}$ counterparts. This is due to the higher porosity, greater mass loss of water, and inferior mechanical properties of higher $\mathrm{w} / \mathrm{c}$ pastes $\left[{ }^{1},{ }^{4}\right]$. When stiff inclusions (quartz and limestone) are added, shrinkage reduces with increasing inclusion concentration. This is expected since stiff inclusions restrain shrinkage of the cement paste (Figures 2a-b). On the other hand, when soft (PCM) inclusions are present, due to a lack of internal restraint, the extent of shrinkage experienced by both the paste and the mortars is similar, independent of inclusion concentration. This shows that dilution (reduction in the paste content), is by no means a cause of shrinkage reduction.

To consider the effects of inclusion stiffness more quantitatively, the drying shrinkage of mortars was estimated using Pickett's and Hobbs models shown in Equations (5-6) below [ $\left.{ }^{5},{ }^{30}\right]$ :

$$
\begin{aligned}
& \varepsilon_{C}=\varepsilon_{P}\left(1-V_{F}\right)^{n}
\end{aligned}
$$

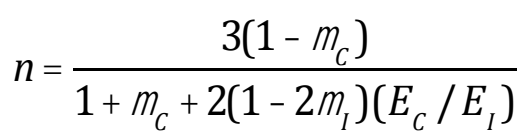

$$
\begin{aligned}
& \varepsilon_{C}=\varepsilon_{P}-\frac{2 K_{I} V_{F}\left(\varepsilon_{P}-\varepsilon_{I}\right)}{K_{P}+K_{I}+V_{F}\left(K_{I}-K_{P}\right)}
\end{aligned}
$$

where, $\varepsilon_{c}, \varepsilon_{l}$ and $\varepsilon_{\mathrm{p}}$ are the shrinkage $(\mu \varepsilon)$ of the mortar (composite), inclusions, and plain paste, respectively, $\mu_{1}$ and $\mu_{c}$ are Poisson's ratios of the inclusions and mortar, respectively, $E_{1}$ and $E_{C}$ are the elastic moduli (GPa) of the inclusions and mortar, respectively, $K_{I}$ and $K_{P}$ are the bulk moduli (GPa) of the inclusion and plain paste, respectively, and $V_{F}$ is the volume fraction of inclusion in the composite (unitless). The elastic moduli of the plain pastes were taken as: 17 GPa $(w / c=0.45), 12 \mathrm{GPa}(\mathrm{w} / \mathrm{c}=0.65)\left[{ }^{31}\right]$, and their Poisson's ratio ( $\mu_{\mathrm{P}}$, unitless) fixed as 0.20 . For quartz, $E_{1}$ and $\mu_{1}$ are set as $64 \mathrm{GPa}$ and 0.22 respectively, for limestone, $E_{1}$ and $\mu_{1}$ are set as $75 \mathrm{GPa}$ and 0.25 respectively, and for PCM inclusions, $E_{1}$ and $\mu_{1}$ are set as $55.7 \mathrm{MPa}$ and 0.49 respectively $\left[{ }^{31}\right]$. The composite elastic modulus $\left(E_{C}\right)$ was calculated using Equation $8(a)$ while the Poisson's ratio of the composite $\left(\mu_{\mathrm{c}}\right)$ represents the Reuss-Voigt-Hill average of the Poisson's ratio of the solids $\left[{ }^{32},{ }^{33}\right]$. 


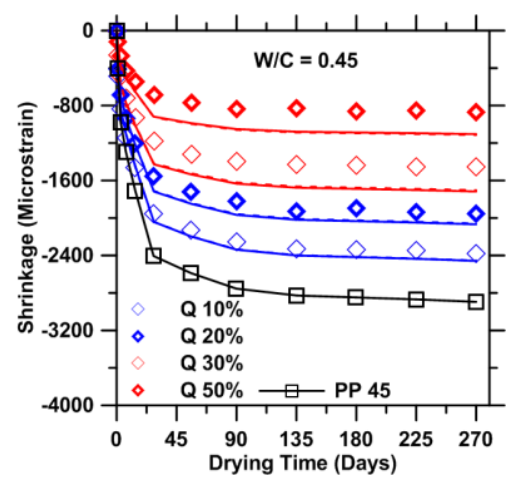

(a)

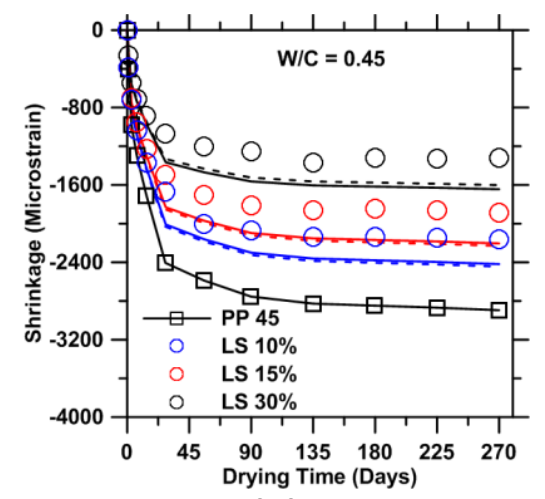

(b)

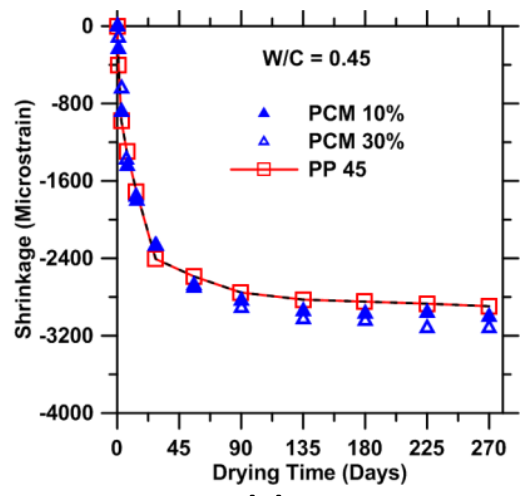

(c)

Figure 2: The shrinkage evolution as a function of drying time for $w / c=0.45$ mixtures with varying dosages of: (a) quartz (Q), (b) limestone (LS) and (c) PCM inclusions. The plain paste (neat cement paste) is abbreviated as "PP". The solid and dashed lines represent the predictions of the composite models of Hobbs and Pickett, respectively. Here and in all subsequent figures, 1 microstrain $=10^{-6} \mathrm{~m} / \mathrm{m}_{\text {ref }}$, where $m_{\text {ref }}$ is the original length of the sample in meters.

In general, Pickett's and Hobbs models provide conservative estimates of mortar shrinkage as seen in Figures (2-3). While Hobbs model can be applied to mortars containing both stiff and soft inclusions, Pickett's model is applicable only to composites containing stiff inclusions since this model neglects the inclusion's compressibility, which in the case of soft inclusions (i.e., PCM's) is substantial. For systems containing soft inclusions, good agreement between the measured and predicted shrinkage is observed so long as the shrinkage of the paste and inclusions is set to be equivalent. This implies that the high compressibility of the PCM inclusions, which are unable to resist the shrinkage of the paste; results in mortar shrinkage similar to the shrinkage of the paste. For a given inclusion volume, the predictions of the composite models are similar independent of inclusion size, which spans between $3 \mu \mathrm{m}$-to-350 $\mu \mathrm{m}\left(d_{50}\right.$, Figure 1$)$. This suggests that for the sizes of inclusions used, ITZ effects are negligible and shrinkage evolution is controlled by the paste and inclusion properties, and volume fractions. At equal dosages, quartz and limestone mortars experience dissimilar shrinkage, with the limestone mixtures shrinking less. While this is expected due to the higher stiffness of limestone inclusions, this is also related to differences in moisture transport properties of both inclusions (addressed later). Surprisingly, it is noted that while higher w/c mixtures experience higher shrinkage (Figure 3), this is not as much as may be expected given their substantially reduced bulk modulus $\left(K_{B}\right)$ vis-à-vis lower w/c mixtures. This is because increasing the w/c while holding $\mathrm{RH}$ constant causes a reduction in liquid saturation which is far more significant for a higher than a lower w/c mixture $\left[{ }^{8}\right]$. This counterbalances the reduction in the bulk modulus, as a result of which increasing the $w / c$ does not result in major enhancements in shrinkage $\left[{ }^{1}\right]$. 


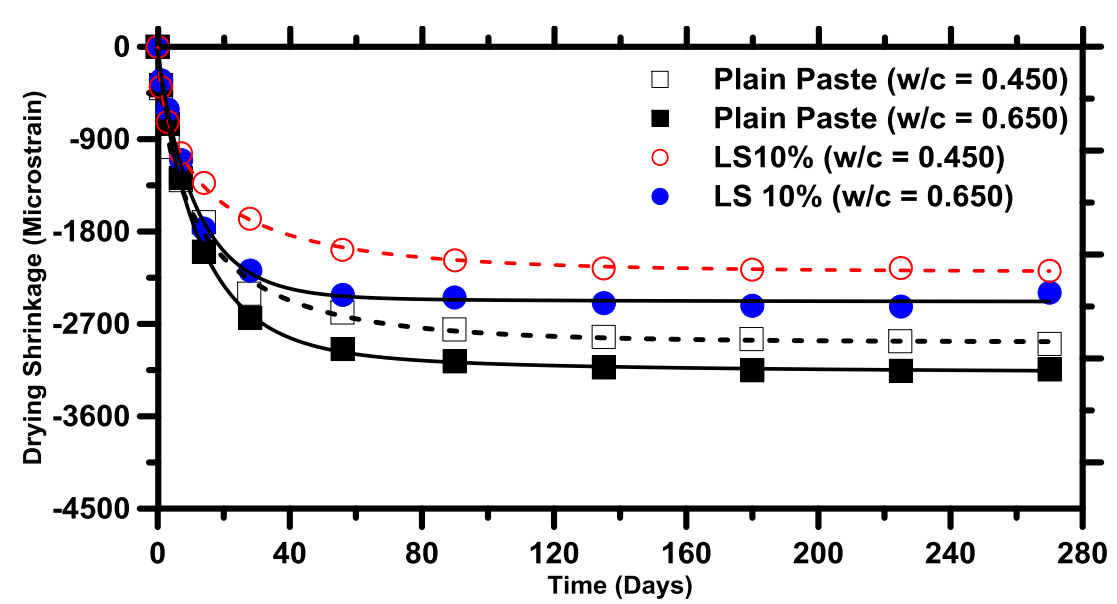

Figure 3: A comparison of shrinkage evolutions for cement pastes for $w / c=0.45$ and $w / c=0.65$ with and without 10 volume \% limestone. By 270 days, the rate of shrinkage is $\approx 0.30 \mu \varepsilon /$ day across all mixtures which represents near-equilibrium shrinkage (N.B.:

At this rate, the shrinkage developed in one month is similar to the measurement accuracy of the comparator). The lines represent best-fits to the data.

Figure 4 shows mass loss as a function of drying time across all inclusion types, dosages, and $w / c$. When normalized by the mass fraction of cement paste in the mixture, the mass loss curves overlap for all mixtures constituted at $w / c=0.45$. This suggests that at low $w / c$, the paste dictates the drying response of the composite regardless of the type and volume of inclusions Contrastingly, for $\mathrm{w} / \mathrm{c}=0.65$ mixtures, while the normalized moisture loss curves for the quartz inclusions and the plain paste overlap, the drying curves of the mixtures containing limestone inclusions remain distinct. Specifically, at similar drying times, including those when the mixtures are expected to reach near-equilibrium conditions, limestone mixtures consistently show higher mass loss compared to quartz and plain paste mixtures. This suggests that when the inclusions are more permeable than the cement paste (i.e., when $k_{L}>k_{p}$, where $k$ is the permeability and $P$, and $L$ denote paste and limestone, respectively), they amplify moisture loss by providing lower resistance escape routes for moisture (e.g., analogous to short-circuit diffusion process $\left.\left[{ }^{34}, 35,36\right]\right)$. It is hypothesized that the water absorbed within the pores of the permeable inclusions (e.g., limestone) during curing, i.e., over and above mixing water, is released at later stages of drying, thus resulting in higher extents of moisture loss (see Figure $4 b)$ at near-equilibrium conditions. At low $w / c(w / c=0.45)$, the permeability of the inclusion is inconsequential in terms of the drying (or shrinkage) response. This is because the paste component in such mixtures has a substantially lower permeability as compared to that of the inclusions, and, therefore, it dictates the rate and extent of moisture transport. It should be noted that the behavior of the $\mathrm{w} / \mathrm{c}=0.65$ mixtures is not an inclusion size-effect, because if so, it would also be observed in the $\mathrm{w} / \mathrm{c}=0.45$ mixtures. 


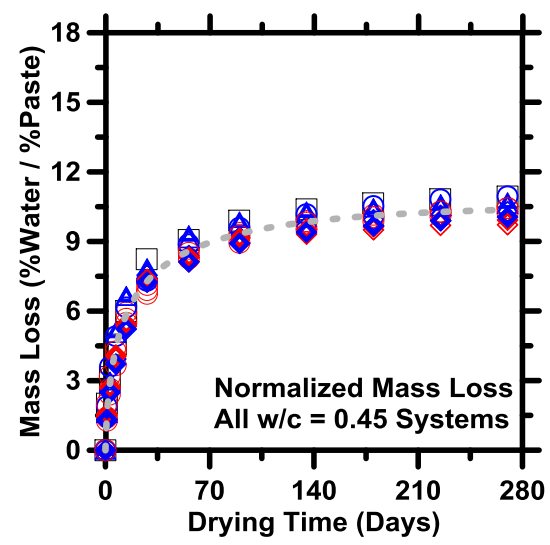

(a)

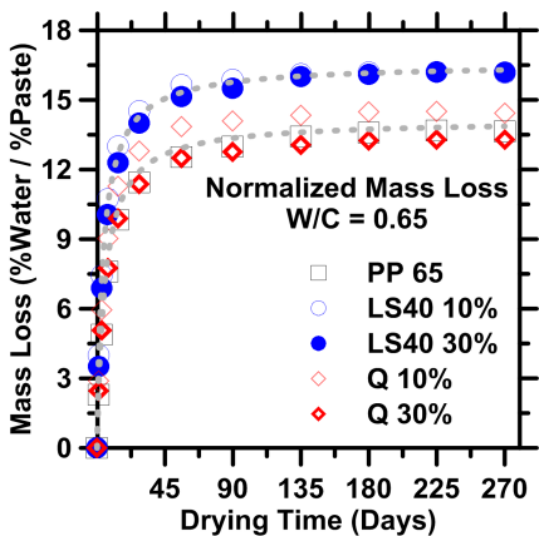

(b)

Figure 4: Moisture loss as a function of drying time for mixtures of: (a) $w / c=0.45$ and (b) $w / c=0.65$ across all inclusion types and dosages. The mass loss is normalized by the paste content in the composite, since this it is the paste that "dries" actively. By 270 days, the rate of mass loss is $\approx 0.002 \%$ /day across all mixtures indicating nearequilibrium conditions. The dashed lines show best-fits to the data.

\subsection{Shrinkage-Mass Loss Correlation}

To correlate shrinkage to mass loss, measured shrinkage was plot against the measured mass loss across all w/c. To account for differences in paste content (i.e., dilution), the measured shrinkage is normalized by the volume fraction of paste while the mass loss is normalized by the mass fraction of cement paste in the composite. From this data (Figure 6a, $6 c)$, linear correlations are noted, although, with, steeper slopes in the case of softer inclusions. The slope is postulated to be a function of the extent of restraint provided by the inclusions, as a result of which softer inclusions or a lower inclusion dosage result in steeper slopes. Past studies $\left[{ }^{37},{ }^{38}\right]$ have noted that the relationship between shrinkage and mass loss of a given cementitious system also depends on the maturity of the sample and the drying conditions (e.g., rate of drying), which in turn may influence long-term delayed (creep) deformations. However, based on the samples' maturity (i.e., age $>56$ days) and the use of identical drying conditions these factors are not expected to influence the shrinkage-mass loss trends.

To rationalize the data, the shrinkage of all mixtures is scaled using a shrinkage multiplier, $M$ (unitless) $\left[{ }^{8}\right]$ to overlay the curves for a given $\mathrm{w} / \mathrm{c}$ and a given drying cycle. Following such rescaling, it is noted that while $w / c=0.45$ systems show a single constant slope shrinkage-mass loss response, the $\mathrm{w} / \mathrm{c}=0.65$ mixtures show a bi-linearity in their shrinkagemass loss behavior (see Figure 6d). The bi-linearity suggests a switch in the size of pores losing moisture. As such, when drying initiates, water is lost dominantly from the larger capillary pores, which produce smaller capillary stresses and volume changes. However, as the large pores are depleted, and the smaller (nanoscale) pores evacuate, shrinkage stresses increase resulting in an increased rate of shrinkage with continued drying. 


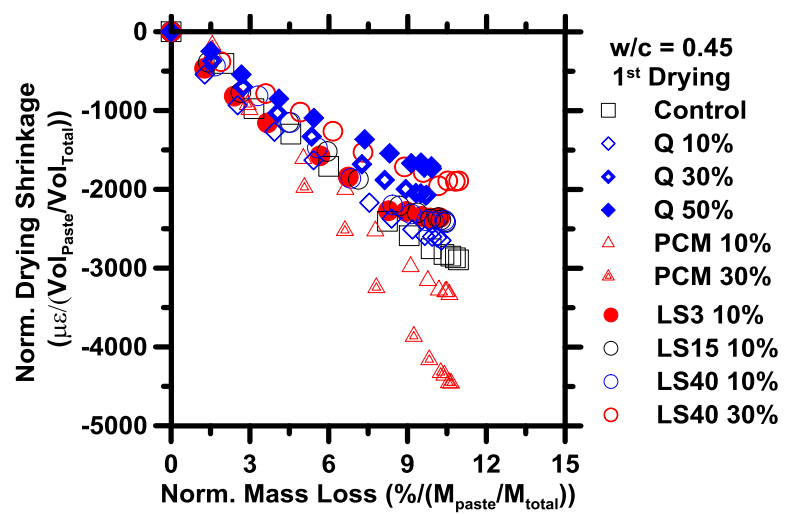

(a)

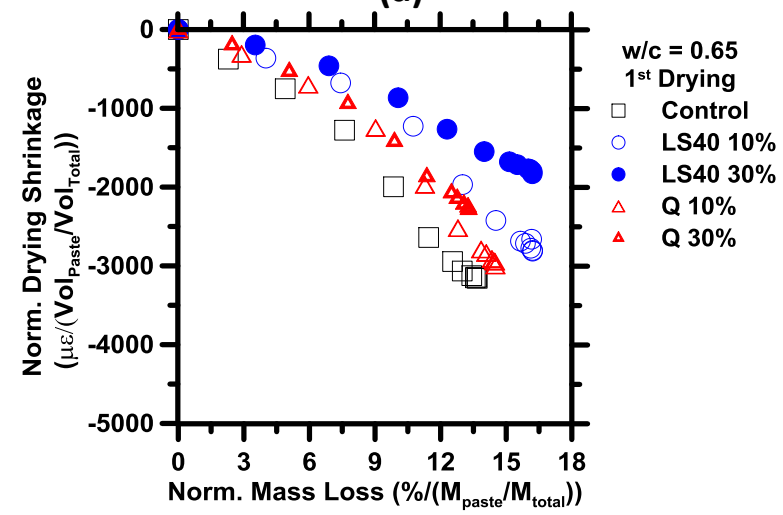

(c)

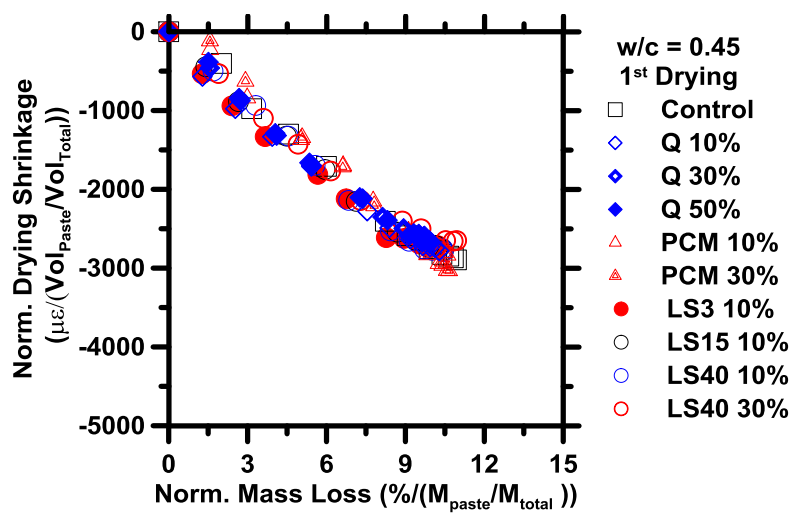

(b)

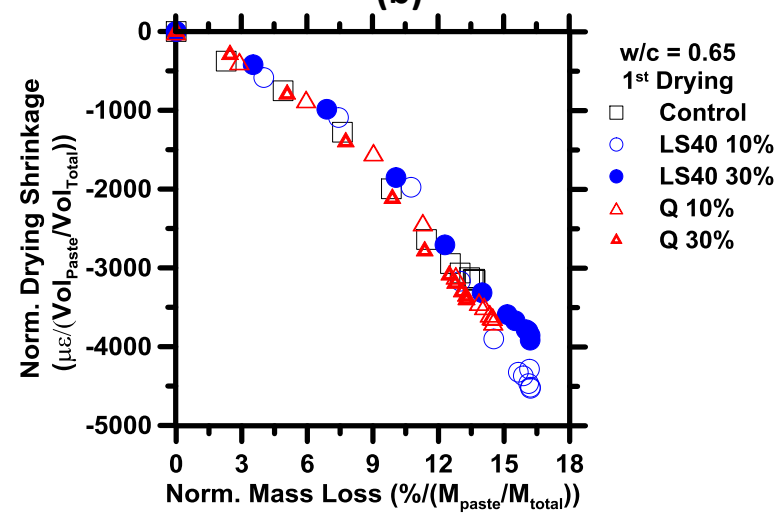

(d)

Figure 6: The measured drying shrinkage normalized by the volume fraction of cement paste as a function of the mass loss of the paste normalized by mass fraction of paste during $1^{\text {st }}$ drying for: $(a$ and $b) w / c=0.45$ and ( $c$ and $d) w / c=0.65$. In ( $b$ and $d)$, the shrinkage is scaled using a shrinkage multiplier, $\mathrm{M}$ (unitless), that is discussed in the text.

While the trends shown in Figure 6 indicate the $1^{\text {st }}$ drying, while $2^{\text {nd }}$ drying, i.e., following rewetting, shows similar behavior, there is one difference that should be pointed out. Up on $2^{\text {nd }}$ drying, mixtures of both $\mathrm{w} / \mathrm{c}$ show a bilinear shrinkage-mass loss relation. It is postulated that the emergence of, or extent of bi-linearity, is more exaggerated upon $2^{\text {nd }}$ drying due to the loss of water with little accompanying shrinkage from fissures and microcracks that may have formed during the $1^{\text {st }}$ drying $\left[{ }^{11}, 12,13,41,39\right]$. Figure 7 traces evolutions of the shrinkage multiplier across $\mathrm{w} / \mathrm{c}$ and drying cycles. It is noted that the shrinkage multiplier scales linearly as a function of the inclusion dosage. In general, $M \geq 1$ for stiff inclusions, and $M \leq 1$ for soft inclusions (see Figure 8). As seen in Figure $8(b)$ for mixtures containing quartz inclusions, $M \approx 1$ up on $2^{\text {nd }}$ drying. This indicates that no (re)scaling is needed for the normalized shrinkage-mass loss curves to overlap on $2^{\text {nd }}$ drying for the quartz mixtures. It is also noted that $\mathrm{M}$ takes smaller values on $2^{\text {nd }}$ drying, as compared to $1^{\text {st }}$ drying. This suggests that for equal mass loss, less shrinkage develops during the second drying; likely due to the increased compliance (i.e., damage induced) of the sample following $1^{\text {st }}$ drying.

The shrinkage multiplier as a function of inclusion dosage is described by the equation, $M=A V_{F}+1$, where $A$ is the slope of the shrinkage multiplier-inclusion volume curves $\left(\%^{-1}\right)$, and 
$V_{F}$ is the volume \% of inclusions. Since $M$ is assumed to dominantly be a function of the restraint provided by the inclusions to the paste's shrinkage, it suggests that $A$ is correlated with the elastic stiffness contrast of the inclusions-to-the-paste matrix, i.e., $E_{l} / E_{p}$, where $E_{1}$ and $E_{p}$ are inclusion and paste stiffnesses respectively (GPa) (e.g., see Figure $7 d$ ). While arguably, this description only considers the pristine modulus of the paste, i.e., before the $1^{\text {st }}$ drying cycle initiates (i.e., which reduces following drying), the data explains why the quality of fit upon $2^{\text {nd }}$ drying is poorer, than for the $1^{\text {st }}$ drying cycle. Importantly, the trend shown in Figure $7(d)$ allows estimations of the shrinkage of a mortar for any combination of inclusion volume and stiffness across drying cycles given data acquired only on the (equivalent $\mathrm{w} / \mathrm{c}$ ) plain paste. It should be noted that given the elastic nature of shrinkage that manifests following the $1^{\text {st }}$ drying cycle, the values of " $A$ " thus determined can be applied to all subsequent drying cycles $\left[{ }^{40}\right]$.

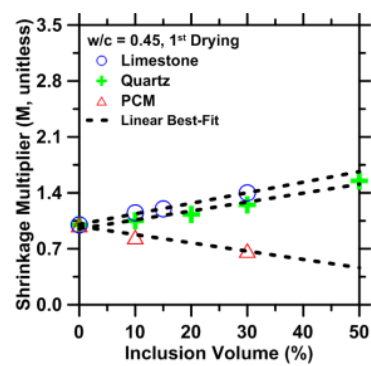

(a)

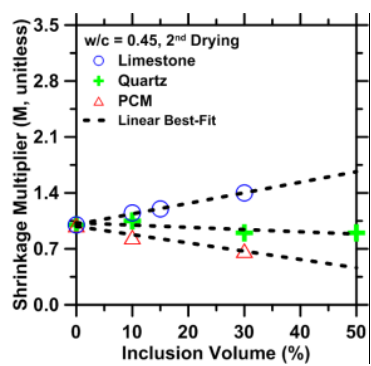

(b)

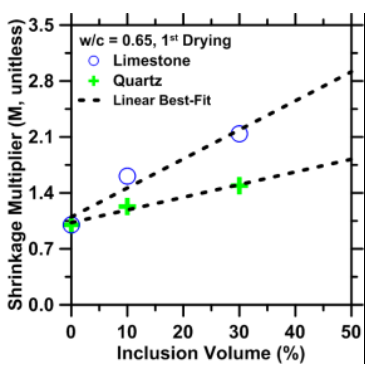

(c)

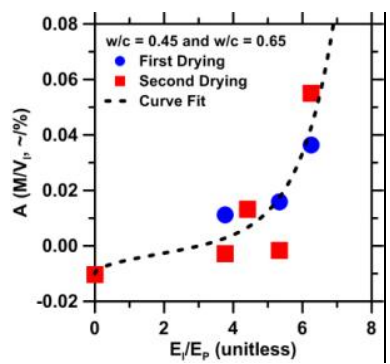

(d)

Figure 7: The shrinkage multiplier, $M$, as a function of the inclusion dosage in the composite for: (a) $w / c=0.45,1^{\text {st }}$ drying, (b) $w / c=0.65,1^{\text {st }}$ drying, (c) $w / c=0.45,2^{\text {nd }}$ drying and (d) The slope $A$ as a function of the stiffness contrast of the inclusions to the matrix $\left(E_{l} / E_{P}\right.$, unitless).

\subsection{Shrinkage Irreversibility}

After 270 days of drying, the samples were rewet in lime-saturated water for 28 days, after which shrinkage and mass loss measurements were reinitiated. After 28 days of rewetting, while all the samples regained mass to a level within $0.03 \%$ of their initial mass, expectedly, a full recovery in strain was not achieved. Figure 8 shows representative shrinkage curves as a function of time across $1^{\text {st }}$ and $2^{\text {nd }}$ drying for $w / c=0.45$. In general, shrinkage experienced during the $2^{\text {nd }}$ drying cycle is reduced, and achieves a near constant value faster than during the $1^{\text {st }}$ drying cycle. Qualitatively similar observations are made in the case of $\mathrm{w} / \mathrm{c}=0.65$ mixtures (not shown).

The extent of shrinkage irreversibility $\left(S_{I_{R}}, \%\right)$ can be quantified in terms of the percentage of ultimate shrinkage experienced during $1^{\text {st }}$ drying that cannot be recovered following rewetting such that: $\mathrm{S}_{\mathrm{IR}}=100\left(\varepsilon_{2 \text { initial }} / \varepsilon_{1 \text { final }}\right)$, where $\varepsilon_{1 \text { final }}$ is the drying strain at the end of the $1^{\text {st }}$ drying cycle (after 270 days) and $\varepsilon_{\text {2initial }}$ is the strain measured after rewetting for 28 days, respectively. The shrinkage irreversibility can be analyzed by considering factors including: (i) reorganization of the $\mathrm{C}-\mathrm{S}-\mathrm{H}$ following drying, and, (ii) damage developed following drying $\left[{ }^{5},{ }^{41}\right]$. Since (i) is a response intrinsic to the $\mathrm{C}-\mathrm{S}-\mathrm{H}$, it is expected to be similar across all pastes independent of $\mathrm{w} / \mathrm{c}$ (i.e., for $\mathrm{RH} \geq 25 \%\left[{ }^{41}\right]$ ). On the other hand, (ii) is expected to be more substantial for higher $\mathrm{w} / \mathrm{c}$ pastes due to the tendency of these mixtures to lose more water and 
their lower stiffness; as compared to low w/c mixtures. Of course, this assumes a similar exposure RH (drying stress) across all systems.

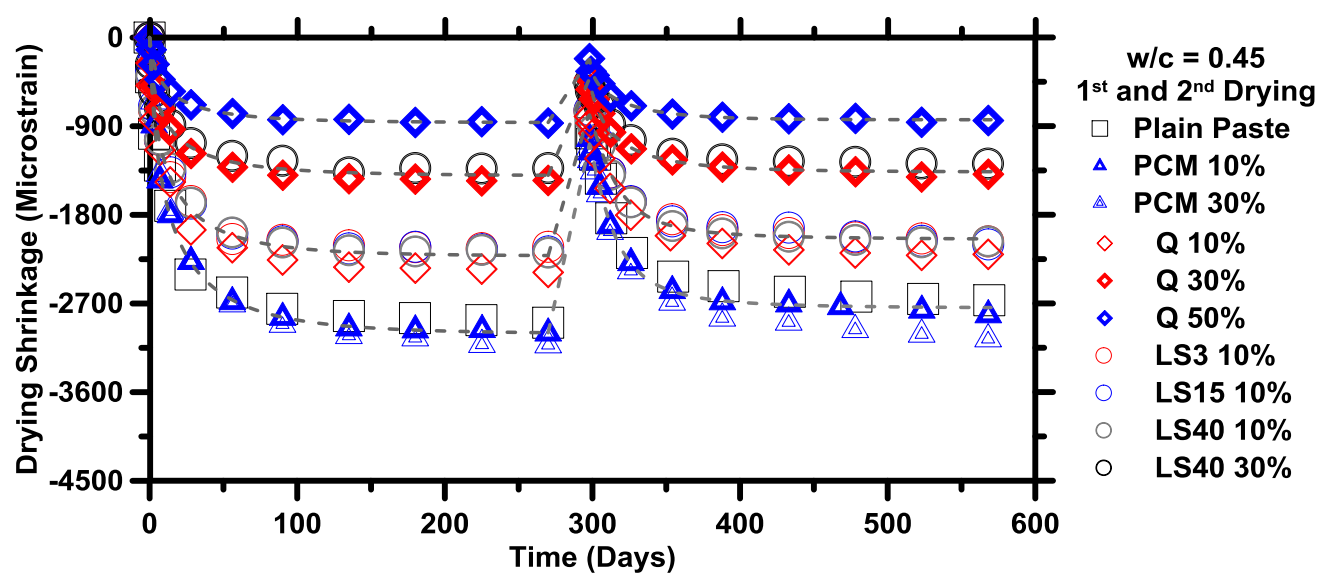

Figure 8: Representative shrinkage curves across $1^{\text {st }}$ and $2^{\text {nd }}$ drying cycles for $w / c=0.45$ for all inclusion types and dosages. The $2^{\text {nd }}$ drying cycle was initiated following a rewetting period of 28 days between the two drying cycles.

Due to the more substantial shrinkage of high w/c pastes, the addition of stiff inclusions is expected to result in more restraint to the shrinkage of the paste in these mixtures (for a fixed inclusion dosage), as compared to lower w/c mixtures. As a result, more damage and shrinkage irreversibility is expected with increasing $\mathrm{w} / \mathrm{c}\left[{ }^{41}\right]$. The restraint offered by stiff inclusions to paste shrinkage can be written as shown in Equation 7(a-c) using a coefficient of elastic restraint $\left(C_{R E}\right.$, unitless) that is a function of a geometry factor $\left(C_{G}\right.$, unitless) and the mechanical properties of the paste and inclusions $\left[{ }^{42}\right]$. The geometry factor $\mathrm{C}_{\mathrm{G}}$ assumes that the paste and inclusions are arranged in a hexagonal array, with the paste enclosing the inclusions (Figure 9a).

$$
\begin{gathered}
V_{I}(\%)=100 \cdot\left(\frac{R_{O I}{ }^{2}}{R_{O P}{ }^{2}}\right) \\
C R E=\frac{C_{G}}{\left(C_{G}+{ }_{P}+\left(1_{I}\right)\left(E_{P} / E_{I}\right)\right)} \\
C_{G}=\frac{\left(\frac{R_{O P}{ }^{2}}{R_{O I}{ }^{2}}\right)+1}{\left(\frac{R_{O P}{ }^{2}}{R_{O I}{ }^{2}}\right)-1}
\end{gathered}
$$

where, $R_{O}$ and $R_{O P}$ are the outer radii of the inclusions and the paste $(\mathrm{m})$ respectively (Figure 9a). As seen in Figure 9(b), the coefficient of elastic restraint is correlated with the ratio of the composite's elastic modulus (i.e., of paste + inclusions) to the elastic modulus of the plain 
cement paste. It should be noted that the composite modulus is calculated using Hobbs model for an inclusion that shows negligible (Equation $8 \mathrm{a}\left[{ }^{26}\right]$ ) or substantial (Equation $8 \mathrm{~b}\left[{ }^{26}\right]$ ) mismatch with respect to the Poisson's ratio of the inclusion [ ${ }^{31,32}$ ].

$$
\begin{gathered}
E_{C}=E_{P}\left[1+\frac{2 V_{I}\left(E_{I}-E_{P}\right)}{\left(E_{I}+E_{P}\right)-V_{I}\left(E_{I}-E_{P}\right)}\right] \\
E_{C}=E_{P}\left[\frac{\left(1-2 \mu_{C}\right)}{\left(1-2 \mu_{P}\right)} \frac{\left(1-V_{I}\right)}{\left(1+V_{I}\right)}\right]
\end{gathered}
$$

where, $\mu_{\mathrm{c}}$, the Poisson's ratio of the composite is determined by averaging the Reuss-Voigt values of the Poisson's ratio of the solid components.

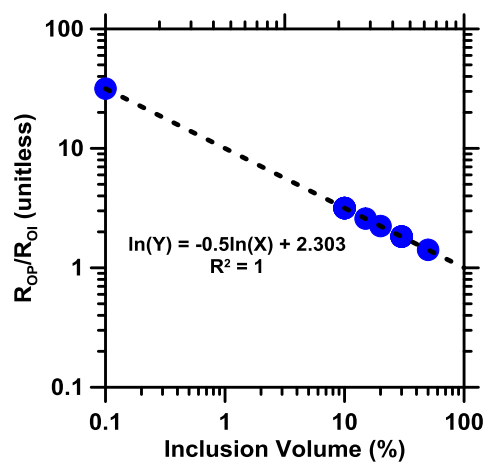

(a)

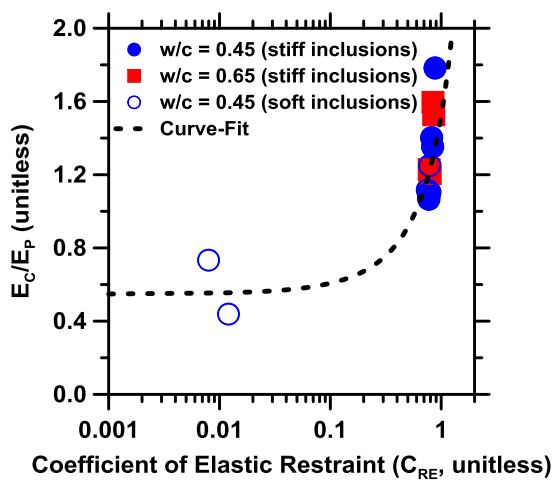

(b)

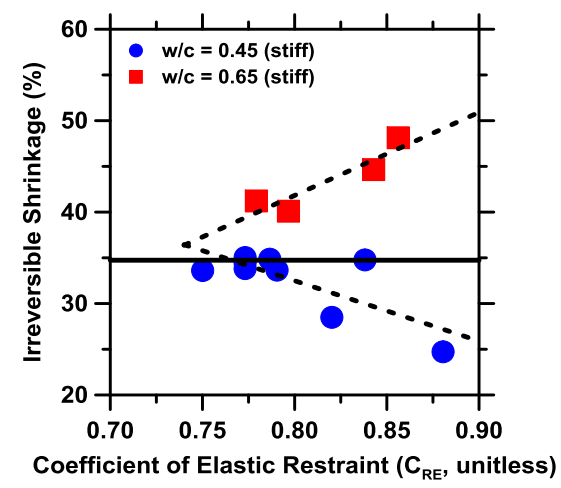

(c)

Figure 9: (a) The paste-to-inclusion radius ratio as a function of the inclusion volume in the composite, (b) The elastic modulus ("stiffness") ratio of the composite-to-the paste matrix as a function of the coefficient of elastic restraint, and, (c) The percentage of irreversible shrinkage as a function of the $C_{R E}$. The bold horizontal line indicates the percentage of shrinkage that is irreversible for: (i) plain pastes, for $\mathrm{w} / \mathrm{c}=0.45,0.55$ and 0.65 and (ii) for inclusions wherein $\mathrm{E}_{1} \ll$ Ep.

When the irreversible shrinkage is plot as a function of the coefficient of elastic restraint, two trends emerge. For $w / c=0.45$, the extent of irreversible shrinkage decreases slightly or remains fixed around $35 \%$ with an increase in the $C_{R E}$ (Figure $9 \mathrm{c}$ ). On the other hand, for $\mathrm{w} / \mathrm{c}=$ 0.65 , the extent of irreversible shrinkage increases with the $C_{R E}$. This indicates that for the same level of restraint, a weak, high $\mathrm{w} / \mathrm{c}$ paste experiences more irreversible shrinkage than its lower $\mathrm{w} / \mathrm{c}$ counterparts. This is postulated to be on account of microstructural changes that occur in the pastes following drying. Specifically, it is hypothesized that low w/c pastes develop less damage, due to their lower shrinkage during the $1^{\text {st }}$ drying cycle. On the other hand, the higher shrinkage of higher $\mathrm{w} / \mathrm{c}$ pastes on $1^{\text {st }}$ drying results in more extensive microstructural changes. Such damage developed, by reducing the extent of capillary stresses that are developed up on $2^{\text {nd }}$ drying, mitigates shrinkage $\left[{ }^{43}\right]$. This also explains why when $E_{1} \ll E_{p}$, the extent of shrinkage irreversibility is similar to the plain paste because the inclusions are unable to restrain the paste's shrinkage. It is important to note that the extent of irreversible shrinkage of the plain 
pastes remains unchanged as a function of $w / c$. This is because in plain paste the shrinkage is controlled by the $\mathrm{C}-\mathrm{S}-\mathrm{H}$, which for similar impositions of drying stress experiences similar alterations (e.g., reorganizations) in its nanostructure and volume (per unit mass) following $1^{\text {st }}$ drying $\left.{ }^{41}\right]$.

\subsection{Moisture Transport Behavior of Cement Paste and Mortar Formulations during Drying}

The drying of a cementitious composite and the resulting shrinkage is a function of the rate and extent of loss of water from the material. Thus, it is valuable to establish the transport properties, i.e., the moisture diffusivity and permeability, of cementitious materials as a function of $w / c$, inclusion dosage etc. $\left[{ }^{13}\right]$. As the material dries from the saturated state, the egress of moisture occurs predominantly via capillary transport, as described by the permeability. However, at lower degrees of saturation, moisture removal occurs not only via capillary transport, but also diffusion; as described by the diffusivity. The drying of cementing materials is often approximated by Fick's $2^{\text {nd }}$ law of diffusion which describes the diffusion of water under an evolving driving force (i.e., water activity gradients). For the case of 1Ddiffusion, Fick's $2^{\text {nd }}$ law can be expressed analytically using a Taylor series expansion of the error function as written by Crank $\left[{ }^{44}\right]$ :

$$
\frac{M_{t}}{M}=1{ }_{n=0}^{n=} \frac{8}{(2 n+1)^{2}{ }^{2}} \exp \left(\frac{D(2 n+1)^{2}{ }^{2} t}{4 l^{2}}\right)
$$

where, $M_{t}$ is the mass loss at a given time $(g), M_{\infty}$ is the mass loss at infinite time $(g), D$ is the total diffusion coefficient (of water in the liquid and vapor states, $\mathrm{m}^{2} / \mathrm{s}$ ), $\mathrm{t}$ is time (s), and I is half the width of the sample $(\mathrm{m})$. Here, 'I' represents the thickness of the sample between the centerline and its exposed faces implying that diffusion is symmetric. To estimate $M_{\infty}$, the experimental mass loss data was fit using a Pearson function $\left[{ }^{45}\right]$ and extrapolated to a large time, in this case 10000 days. Once $M_{\infty}$ was obtained, given knowledge of $M(t)$ and I, Equation (9) was solved using MATLAB to determine the diffusion coefficient as a function of drying time $\left[{ }^{40}, 44\right]$.

Figure 9 shows the evolution of the diffusion coefficient with drying time for both w/c and across $1^{\text {st }}$ and $2^{\text {nd }}$ drying cycles. For both drying cycles, the diffusion coefficient decreases by an order of magnitude over the duration of drying. The decrease in the diffusion coefficient is on account of the progressive removal of water from larger to the smaller pores, the latter of which are more resistant to the removal of water. Expectedly, a higher w/c features a higher diffusion coefficient (Figure 9c), due to its larger overall porosity and coarser pores. Drying increases the diffusion coefficient, i.e., from the $1^{\text {st }}$ to $2^{\text {nd }}$ drying cycle, by a factor of two; likely due to the formation of fissures up on drying. Importantly, the diffusion coefficient is on the same order of magnitude for all mixtures in spite of differences in $\mathrm{w} / \mathrm{c}$, and inclusion dosages; suggesting a response that is controlled by the C-S-H component of the cement pastes $\left[{ }^{46},{ }^{47}\right]$. 


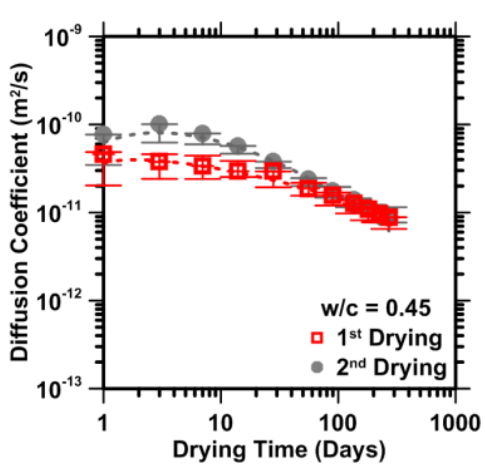

(a)

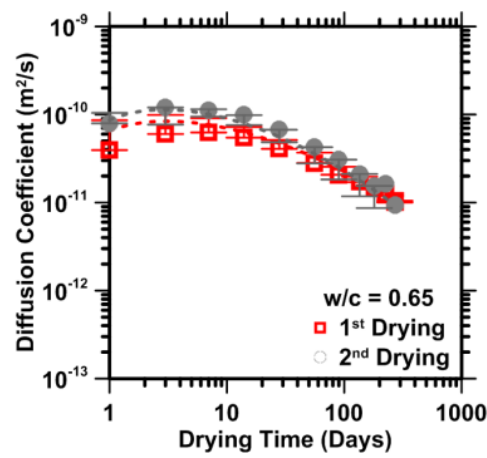

(b)

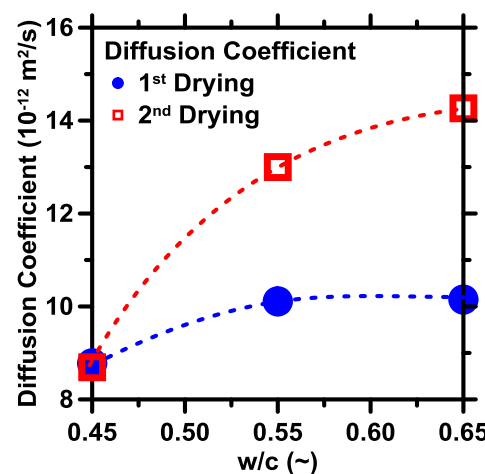

(c)

Figure 9: The calculated total moisture diffusion coefficients during $1^{\text {st }}$ and $2^{\text {nd }}$ drying for: (a) $\mathrm{w} / \mathrm{c}=0.45$ plain paste, and, (b) $\mathrm{w} / \mathrm{c}=0.65$ plain paste. The bars indicate the maximum and minimum diffusion coefficient across all mixtures, inclusion types and dosages for a given w/c. (c) The total moisture diffusion coefficient during $1^{\text {st }}$ and $2^{\text {nd }}$ drying for the plain pastes across all $\mathrm{w} / \mathrm{c}$ after 270 days of drying. The dashed lines represent exponential fits.

Figure 10 shows the evolution of the diffusion coefficient with liquid water saturation (S) across $\mathrm{w} / \mathrm{c}$ and drying cycles. The values of $\mathrm{S}$ were determined via knowledge of: (a) the timedependent mass of the (initially) water saturated mixtures, and, (b) the evaporable water content of the pastes established by oven drying for 24 hours at $110^{\circ} \mathrm{C}$. The diffusion coefficients decrease with saturation $\left[{ }^{48}\right]$. This is expected because the egress of moisture is slowed after the capillary pores are emptied, and water removal occurs dominantly from the smaller gel pores. Also, the reduction in the diffusion coefficients is also linked to a decrease in the driving force for drying; the RH gradient, which reduces with time and saturation.

For both $\mathrm{w} / \mathrm{c}$, the diffusion coefficients during $2^{\text {nd }}$ drying are somewhat higher compared to those determined for $1^{\text {st }}$ drying; a reflection of damage that develops during the $1^{\text {st }}$ drying. However, as saturation decreases, the $2^{\text {nd }}$ drying diffusion coefficients decline sharply and are similar to those seen on $1^{\text {st }}$ drying. This is due to water removal from the gel porosity, which remains essentially unaltered from the $1^{\text {st }}$ to $2^{\text {nd }}$ drying - over this $\mathrm{RH}$ range - as previously shown by Jennings et al. $\left[{ }^{41}\right]$. It is however expected that dissimilarities in moisture diffusion coefficients across $1^{\text {st }}$ and $2^{\text {nd }}$ drying cycles would magnify if the samples were subjected to yet more severe drying (i.e., $\mathrm{RH}<30 \%$ ), due to significant changes in the C-S-H structure $\left[{ }^{41}\right]$. 


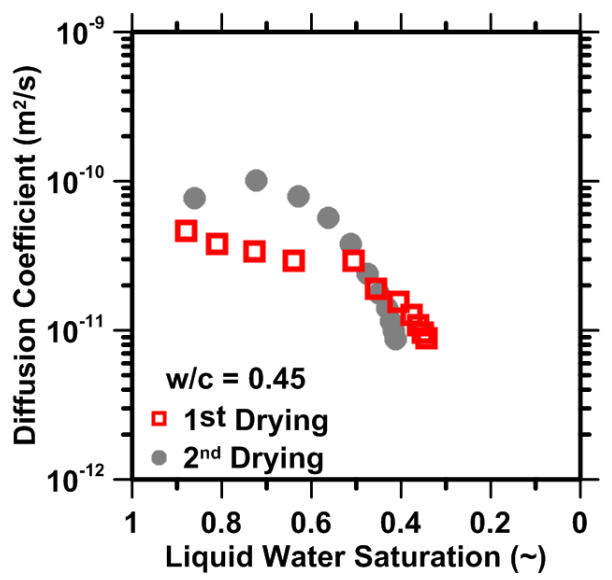

(a)

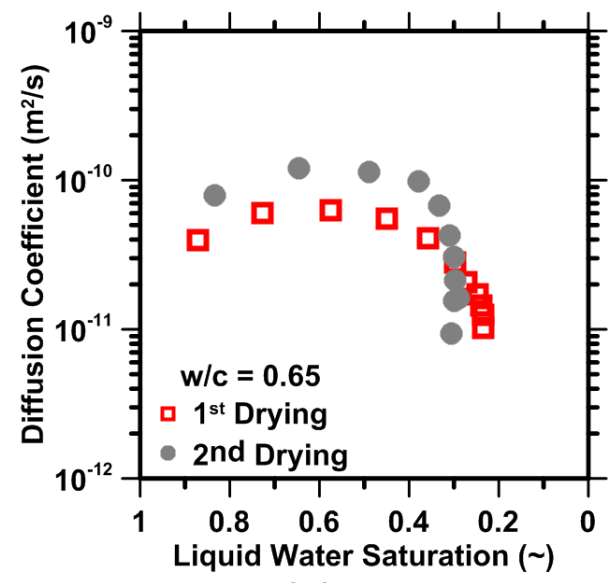

(b)

Figure 10: The total moisture diffusion coefficients as a function of liquid water saturation during $1^{\text {st }}$ and $2^{\text {nd }}$ drying for the: (a) $w / c=0.45$, and, (b) $w / c=0.65$ plain pastes.

The total diffusion coefficient $\left(D, \mathrm{~m}^{2} / \mathrm{s}\right)$ calculated from Fick's $2^{\text {nd }}$ law (Equation 9 ) can be written as the sum of the liquid and the vapor diffusion coefficients as noted in Equation (10) $\left[{ }^{13}\right]$ :

$$
\begin{gathered}
D=D_{l}(S)+D_{V}(S) \\
D_{V}(S)=-\frac{d P_{C}(S)}{d S}\left(\frac{M}{\rho_{l} R T}\right)^{2} D_{v e}(S) \frac{P_{v s}}{\phi} \exp \left(\frac{M}{\rho_{l} R T} P_{C}(S)\right) \\
D_{v e}(S)=D_{v 0} \cdot\left[\phi^{h} \cdot(1-S)^{j}\right] \\
P_{C}(S)=a\left(S^{-b}-1\right)^{\left(1-\frac{1}{b}\right)}
\end{gathered}
$$

where, $D_{\text {I }}$ is the liquid water diffusion coefficient $\left(\mathrm{m}^{2} / \mathrm{s}\right), D_{v}$ is the water vapor diffusion coefficient $\left(\mathrm{m}^{2} / \mathrm{s}\right), \mathrm{S}$ is the liquid saturation level $(0 \leq \mathrm{S} \leq 1$, unitless; Equation $11 \mathrm{a}), \mathrm{M}$ is the molar mass of water $\left(18.02 \mathrm{~g} /\right.$ mole), $\rho_{\mathrm{l}}$ is the density of water $\left(\mathrm{kg} / \mathrm{m}^{3}\right), \mathrm{R}$ is the gas constant (8.314 J/K.mole), $\phi$ is the porosity (unitless, as obtained from MIP $\left[{ }^{49}\right]$ ), $p_{v s}$ is the saturated vapor pressure of water vapor $\left(3.170 \mathrm{kPa}\right.$ at $\left.25^{\circ} \mathrm{C}\right), \mathrm{D}_{\text {ve }}$ is the effective vapor diffusion coefficient $\left(\mathrm{m}^{2} / \mathrm{s}\right), D_{v 0}$ is the free water vapor diffusion coefficient $\left(2.47 \times 10^{-5} \mathrm{~m}^{2} / \mathrm{s}\right), \mathrm{h}$ and $\mathrm{j}$ are fitting parameters, where $h=6.0$ and $j=3.3$ respectively, and $p_{c}(S)$ is the liquid saturation dependent capillary pressure curve that is identified by fitting Van-Genuchten's equation to measured water sorption isotherms for pastes of different $w / c$, where $a$ and $b$ are fitting parameters (see Figure $11 \mathrm{a}$ and $11 \mathrm{~b}$ ) $\left[{ }^{50}\right]$. The diffusion coefficients noted above are a function of the liquid saturation level as the presence, or lack of water influences transport $\left[{ }^{49}\right]$. Equations $10(a-d)$ permit quantification of $D_{1}$, which can be used to estimate the intrinsic liquid water permeability of the composite using Equation (11): 


$$
\begin{gathered}
K_{l}(S)=\frac{-D_{l}(S) \cdot \phi \cdot \eta}{\left(\frac{d P_{C}(S)}{d S} \cdot K_{r l}(S)\right)} \\
K_{r l}(S)=\sqrt{S}\left[1-\left(1-S^{b}\right)^{1 / b}\right]^{2}
\end{gathered}
$$

where, $\eta$ is the viscosity of water $(0.89 \mathrm{mPa} \cdot \mathrm{s})$, and $\mathrm{k}_{\mathrm{rl}}(\mathrm{S})$ is liquid saturation-dependent relative permeability of the material (unitless) $\left[{ }^{49}\right]$.

Figure $11(\mathrm{c})$ shows the intrinsic permeability $\left(\mathrm{K}_{\mathrm{l}}\right)$ of the cement pastes as a function of $\mathrm{w} / \mathrm{c}$. The intrinsic permeability scales with $\mathrm{w} / \mathrm{c}$. This is expected because of the enhancement in the overall porosity and pore-connectivity with increasing $\mathrm{w} / \mathrm{c}$, which facilitates moisture transport. It should be noted that, while the diffusion coefficient (D) changes slightly (Figure 9c), from the $1^{\text {st }}$ to the $2^{\text {nd }}$ drying cycle, the intrinsic permeability increases around one order of magnitude from the $1^{\text {st }}$ t to the $2^{\text {nd }}$ drying cycle. This is on account of the intrinsic permeability being more sensitive to the presence of fissures (i.e., formed as a result of drying during the $1^{\text {st }}$ drying cycle), as opposed to the diffusivity which is dictated by the movement of molecular water through the $\mathrm{C}-\mathrm{S}-\mathrm{H}$. It is noted that the intrinsic permeability $\left(\mathrm{K}_{l}(\mathrm{~S})\right.$, for $\left.\mathrm{S}=1\right)$ estimated from the mass loss curves is in very good agreement with the value determined from the KatzThompson equation $\left[{ }^{49}\right.$ ] suggesting that so long as the gradient of the capillary pressure curve $\left(\mathrm{dP}_{\mathrm{c}}(\mathrm{S}) / \mathrm{dS}\right)$ is known, mass loss data offers a quick means to estimate the transport properties of cementing materials.

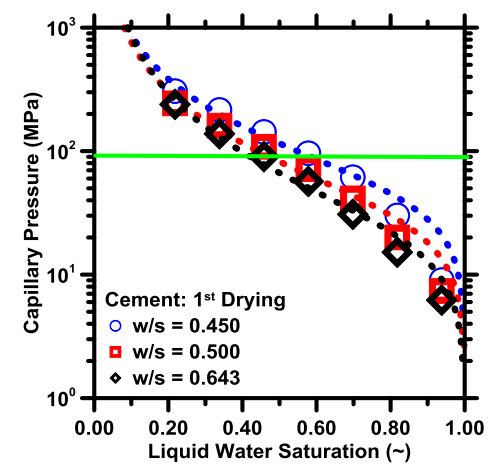

(a)

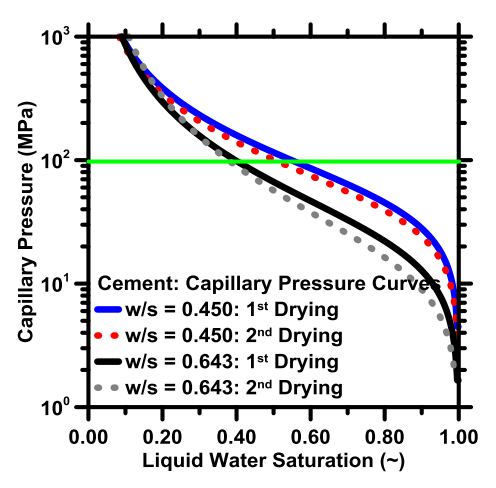

(b)

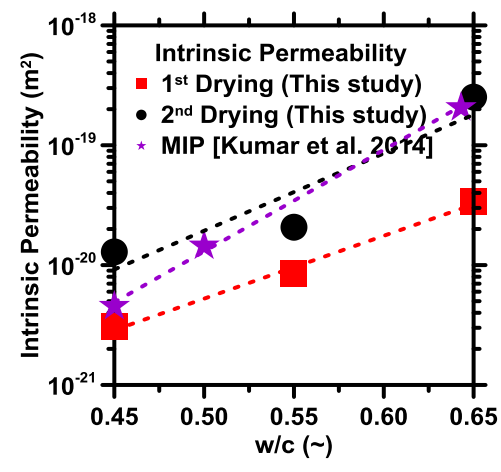

(c)

Figure 11: (a) The capillary pressure curves established using the $1^{\text {st }}$ desorption isotherm for different w/c, and its fitting using van Genuchten's equation (dashed lines). (b) The van Genuchten fits of capillary pressure curves for $1^{\text {st }}$ and $2^{\text {nd }}$ drying cycles for cement pastes across a range of $\mathrm{w} / \mathrm{c}$. The solid green line shows the capillary pressure developed at $\mathrm{RH}=50 \%$ ( 95.4 $\mathrm{MPa})\left[{ }^{49}\right]$. (c) The intrinsic permeability as a function of $w / c$ across $1^{\text {st }}$ and $2^{\text {nd }}$ drying cycles. The intrinsic permeability quantified using the Katz-Thompson relation is shown for comparison $\left[{ }^{49}\right]$.

The dashed lines show exponential fits to the measured data. 


\subsection{Summary and Conclusions}

This paper critically reexamines the influence of the inclusion size, volume and stiffness on the drying and shrinkage behavior of cementitious mixtures. It is seen that in low w/c pastes, the shrinkage of mortars is dominated by the shrinkage of the paste component, and, thereby, only dependent on inclusion dosage and stiffness. However, in pastes prepared at high(er) w/c, the permeability of inclusions also influences the shrinkage response. For example, if inclusions are more permeable than the paste, they facilitate moisture loss through their lower resistance pore network. Furthermore, it is seen that the ultimate shrinkage of the paste measured after the primary $\left(1^{\text {st }}\right)$ and secondary $\left(2^{\text {nd }}\right)$ drying cycles are dissimilar, wherein the extent of shrinkage irreversibility depends on the inclusion stiffness, as well as the paste's w/c. By offering a higher restraint to shrinkage, stiff inclusions produce a higher level of irreversible shrinkage in higher $\mathrm{w} / \mathrm{c}$ pastes. This appears to be directly linked to the stiffness contrast between the cement paste and the inclusions. Significantly, the stiffness contrast is also wellcorrelated with the rescaling shrinkage multiplier that permits construction of unified shrinkage-mass loss curves across pastes prepared at different $\mathrm{w} / \mathrm{c}$, and using different types and volumes of inclusions.

Analyses of time-dependent mass loss (drying) curves permits determination of the key moisture transport coefficients (i.e., intrinsic permeability, and moisture diffusivity) as a function of the drying time and w/c. It is noted that both of the transport coefficients are dictated by the paste component, and increase with increasing w/c of the paste. Both permeability and diffusivity are enhanced after the first drying cycle, due to an increase in the porosity (or microcracking) in the composite. Taken together, the outcomes improve our insight into the drying and shrinkage behavior of cementitious materials, and, approaches/models for their estimation.

\section{Acknowledgements}

The authors acknowledge full financial support for this research provisioned by the University of California, Los Angeles (UCLA) and National Science Foundation (CMMI: 1066583 and 1130028). The contents of this paper reflect the views and opinions of the authors, who are responsible for the accuracy of the datasets presented. This research was conducted in the Laboratory for the Chemistry of Construction Materials (LC $\left.{ }^{2}\right)$ and the Molecular Instrumentation Center (MIC) at the University of California, Los Angeles. As such, the authors acknowledge the support that has made these laboratories and their operations possible.

\section{References}

${ }^{1}$ Bissonnette, B., Pierre, P., \& Pigeon, M., 'Influence of key parameters on drying shrinkage of cementitious materials', Cement and Concrete Research, 29, pp. 1655-1662, (1999)

${ }^{2}$ Hobbs, D.W., 'Influence of aggregate restraint on the shrinkage of concrete', ACl Journal 71(30), pp. 445-450, (1974)

${ }^{3}$ Bentz, D. P., Geiker, M. R., and Hansen, K. K, 'Shrinkage-reducing admixtures and early age desiccation in cement pastes and mortars', Cement and Concrete Research, 31, pp. 1075-1085, (2001) 
${ }^{4}$ Hansen, W., 'Drying shrinkage mechanisms in portland cement paste', Journal of the American Ceramic Society, 70(5), pp. 323-328, (1987)

${ }^{5}$ Pickett, G., 'Effect of aggregate on shrinkage of concrete and a hypothesis concerning shrinkage', ACl Journal, 27 (5), pp. 581-590, (1956)

6 Juenger, M. C. G., and Jennings, H. M., 'Examining the relationship between the microstructure of calcium silicate hydrate and drying shrinkage of cement pastes, Cement and Concrete Research 32, pp. 289-296, (2002)

${ }^{7}$ Sakata, K., 'A study on moisture diffusion in drying and drying shrinkage of concrete', Cement and Concrete Research, 13, pp. 216-224, (1983)

${ }^{8}$ Sant, G., Kumar, A., Patapy, C., Le Saout, G., and Scrivener, K., 'The influence of sodium and potassium hydroxide on volume changes in cementitious materials, Cement and Concrete Research 42, pp. 1447-1455, (2012)

${ }^{9}$ Weiss, J., Lura, P., Rajabipour, F., and Sant, G., 'Performance of shrinkage-reducing admixtures at different humidities and at early ages', ACI Materials Journal, 105(5), pp. 478-486, (2008)

${ }^{10}$ Samdariya, A., Sant, G., Dehadrai, M., and Weiss, W. J., 'The Influence of a CaO-Based Expansive Additive on Volume Changes, Residual Stress Development and Strength Evolution in Cementitious Materials', International RILEM Conference on Concrete Durability and Service Life Planning 'ConcreteLife '09', Haifa, Israel, pp. 8, (2009)

${ }^{11}$ Feldman, R.F., and Sereda, P.J., 'Sorption of water on compacts of bottle-hydrated cement. I. The sorption and length-change isotherms', Journal of Applied Chemistry, 14, pp. 87-93, (1964)

12 Baroghel-Bouny, V., Mainguy, M., Lassabatere, T., and Coussy, O., 'Characterization and identification of equilibrium and transfer moisture properties for ordinary and high performance cementitious materials', Cement and Concrete Research, 29, pp. 1225-1238, (1999)

${ }^{13}$ Baroghel-Bouny, V., Thiery, M., Barberon, F., Coussy, O., Villain, G., 'Assessment of transport properties of cementitious materials. A major challenge as regards durability? Transfert dans les géomatériaux, pp. 671-696, (2007)

${ }^{14}$ Bentz, D. P., Snyder, K. A., Cass, L. C., and Peltz, M. A., 'Doubling the Service Life of Concrete. I: Reducing Ion Mobility Using Nanoscale Viscosity Modifiers', Cement and Concrete Composites, 30(8), pp. 674-678, (2008)

${ }^{15}$ Nilsson, L.O., 'Long term moisture transport in high performance concrete', Materials and Structures 35, pp. 641-649, (2002)

${ }^{16}$ Wong, S.F., Wee, T.H., Swaddiwudhipong, S., and Lee, S. L., 'Study of water movement in concrete', Magazine of Concrete Research, 53(3), pp. 205-220, (2001)

${ }^{17}$ Feldman, R. F., and Sereda, P. J., 'A model for hydrated Portland cement paste as deduced from sorption-length change and mechanical properties', Materiaux et Construction, 1(6), pp. 509-520, (1968)

${ }^{18}$ Taylor, H. F. W., Cement Chemistry, $2^{\text {nd }}$ Edition, Thomas Telford, (1997)

19 http://www.micronal.de/portal/load/fid443847/BASF_Micronal_PCM_Brochure\%202009_En glish.pdf, last verified, July 2013

${ }^{20}$ ASTM International, Annual book of ASTM Standards: Cement, Concrete and Aggregates, 2014 
${ }^{21}$ Di Bella, C., Griffa, M., Ulrich, T.J., Lura, Pietro, 'Early-age elastic properties of cement-based materials as a function of decreasing moisture content', Cement and Concrete Research, 89, pp. 87-96, (2016)

${ }^{22}$ Weiss, J., Lura, P., Rajabipour, F., Sant, G. 'Performance of shrinkage-reducing admixtures at different humidities and at early ages', ACI Materials Journal, 105(5), pp. 478-486, (2008)

${ }^{23}$ Di Bella, C., Wyrzykowski, M., Lura, P., 'Evaluation of the ultimate drying shrinkage of cementbased mortars with poroelastic models', Materials and Structures, 50(1), p.52, (2017)

${ }^{24}$ Vlahinic, I., Jennings, H.M., and Thomas, J.J., 'A constitutive model for drying of a partially saturated porous material', Mechanics of Materials, 41, pp. 319-328, (2009)

${ }^{25}$ Mackenzie, J. K., 'The elastic constants of a solid containing spherical holes', Proceedings of the Physical Society, Section B, 63(1), pp. 2-11, (1950)

${ }^{26}$ Bentz, D.P., Garboczi, E.J., Quenard, D.A., 'Modelling drying shrinkage in reconstructed porous materials: application to porous Vycor glass', Modeling and Simulation in Materials Science and Engineering 6, pp. 211-236, (1998).

${ }^{27}$ Sun, Z., and Scherer, G. W., 'Effect of air voids on salt scaling and internal freezing', Cement and Concrete Research, 40, pp. 260-270, (2010)

${ }^{28}$ Grasley, Z. C., Scherer, G. W., Lange, D. A., and Valenza, J. J., 'Dynamic pressurization method for measuring permeability and modulus: II. Cementitious materials', Materials and Structures, 40(7), pp. 711-721, (2007)

${ }^{29}$ Powers, Treval Clifford. 'Structure and physical properties of hardened Portland cement paste.' Journal of the American Ceramic Society 41, no. 1 (1958): 1-6.

${ }^{30}$ Hobbs, D.W., 'The dependence of the bulk modulus, Young's modulus, creep, shrinkage, and thermal expansion of concrete upon aggregate volume concentration', Materials and Structures, 4(20), pp. 107-114, (1971)

${ }^{31}$ Falzone, G., Puerta Falla, G., Wei, Z., Zhao, M., Kumar, A., Neithalath, N., Pilon, L., and Sant, G., 'The Mechanical Properties of Cementitious Composites Containing Soft and Stiff Inclusions: Experiments and Micromechanical Model Predictions', Composites: Part A, pp. 14, (2015).

32 Falzone, G., Puerta Falla, G., Wei, Z., Zhao, M., Kumar, A., Bauchy, M., Sant, G, 'The influences of soft and stiff inclusions on the mechanical properties of cementitious composites', Cement and Concrete Composites, 71, pp. 153-165, (2016).

${ }^{33}$ Hill, R., 'The elastic behavior of a crystalline aggregate, Proceedings of the Physical Society, Section A, 65(5), pp. 349-354, (1952).

${ }^{34}$ Cao, Y., Zavaterri, P., Youngblood, J., Moon, R., Weiss, J., 'The influence of cellulose nanocrystal additions on the performance of cement paste', Cement and Concrete Composites, 56, pp. 73-83, (2015).

${ }^{35}$ Cao, Y., Tian, N., Bahr, D., Zavattieri, P. D., Youngblood, J., Moon, R. J., Weiss, J, 'The influence of cellulose nanocrystals on the microstructure of cement paste', Cement and Concrete Composites, 74, pp. 164-173, (2016).

${ }^{36}$ Atkinson, A., R. I. Taylor, and A. E. Hughes. 'A quantitative demonstration of the grain boundary diffusion mechanism for the oxidation of metals', Philosophical Magazine A 45(5), pp. 823-833, (1982) 
${ }^{37}$ Lura, P., Jensen, O. M., \& van Breugel, K., 'Autogenous shrinkage in high-performance cement paste: an evaluation of basic mechanisms', Cement and Concrete Research, 33(2) pp. 223-232, (2003)

${ }^{38}$ Grasley, Z.C., Lange, D.A. and Matthew, D.D., 'Internal relative humidity and drying stress gradients in concrete', Materials and Structures, 39(9), pp.901-909, (2006)

${ }^{39}$ Idiart, A., Bisschop, J., Caballero, A. and Lura, P., 'A numerical and experimental study of aggregate-induced shrinkage cracking in cementitious composites', Cement and Concrete Research, 42(2), pp.272-281 (2012)

${ }^{40}$ Helmuth, R.A., 'The reversible and irreversible drying shrinkage of hardened portland cement and tricalcium silicate pastes', Journal of the PCA Research and Development Laboratories, 9(2), pp. 8-21, (1967)

${ }^{41}$ Jennings, H., Kumar, A., and Sant, G., 'Quantitative discrimination of the nano-pore-structure of cement paste during drying: New insights from water sorption isotherms', Cement and Concrete Research, pp. 12, (accepted, 2015)

${ }^{42}$ Pease, B., Neuwald, A., Weiss, J., The Influence of Aggregates on Early Age Cracking in Cementitious Systems, Proceedings of "Celebrating Concrete: Role of Concrete in Sustainable Development: An International Symposium dedicated to Prof. Surendra Shah", Northwestern University, Evanston, IL, pp. 329-338, (2003)

${ }^{43}$ Idiart, A., Bisschop, J., Caballero, A., Lura, P., 'A numerical and experimental study of aggregate-induced shrinkage cracking in cementitious composites', Cement and Concrete Research, 42(2), pp. 272-281, (2012)

${ }^{44}$ Crank, J., 'The mathematics of diffusion', Oxford University Press, $2^{\text {nd }}$ Edition, p. 414, (1975)

${ }^{45}$ Pearson, K., 'Contributions to the Mathematical Theory of Evolution. II. Skew Variation in Homogeneous Material', Philosophical Transactions of the Royal Society of London A, 186, pp. 343-414, (1895)

${ }^{46}$ Bentz, D. P., and Garboczi, E. J., Computer modeling of the interfacial transition zone: Microstructure and properties, RILEM Report \# 20, Editors: A. Alexander, G. Arliguie, G. Ballivy, A. Bentur and J. Marchand, Chapter 20, pp. 349-385, 1999

${ }^{47}$ Wong, H. S., Zobel, M., Buenfeld, N. R., and Zimmerman, R. W., 'Influence of the interfacial transition zone and microcracking on the diffusivity, permeability and sorptivity of cementbased materials after drying', Magazine of Concrete Research, 61(8), pp. 571-589, (2009)

${ }^{48}$ Martys, N.S., 'Diffusion in Partially-Saturated Porous Materials', Materials and Structures, 32, pp. 555-562 (1999)

${ }^{49}$ Kumar, A., Ketel, S., Vance, K.,Oey, T., Neithalath, N., and Sant, G., 'Water Vapor Sorption in Cementitious Materials-Measurement, Modeling, and Interpretation', Transport in Porous Media 103(1), pp. 69-98, (2014)

${ }^{50}$ Van Genuchten, M.T., 'A closed-form equation for predicting the hydraulic conductivity of unsaturated soils', Journal of the Soil Science Society of America, 44 (5), pp. 891-898, (1980) 